\title{
Metformin and mTOR Inhibitors: Allies against Ovarian and Breast Cancers
}

Isabella dos Santos Guimarães ${ }^{1}$, Nayara Gusmão Tessarollo ${ }^{1}$, Diandra Zipinotti dos Santos ${ }^{2}$, Marcele Lorentz Mattos de Souza ${ }^{2}$, Taciane Barbosa Henriques ${ }^{1}$, Ian Victor Silva ${ }^{1,3}$ and Leticia Batista Azevedo Rangel ${ }^{1,4^{*}}$

${ }^{1}$ Biotechnology Program/RENORBIO, Health Sciences Center, Federal University of Espirito Santo, Vitoria, ES, Brazil

${ }^{2}$ Pharmacology and Biochemistry Program, Health Sciences Center, Federal University of Espirito Santo, Vitoria, ES, Brazil

${ }^{3}$ Department of Morphology, Health Sciences Center, Federal University of Espirito Santo, Vitoria, ES, Brazil

${ }^{4}$ Department of Pharmaceutical Sciences, Health Sciences Center, Federal University of Espirito Santo, Vitoria, ES, Brazil

"Corresponding author: Leticia Batista Azevedo Rangel, Department of Pharmaceutical Sciences, Health Sciences Center, Federal University of Espirito Santo, Vitoria, ES, Brazil, Tel: +552733357539; E-mail: Ibarangel@yahoo.com

Received date: June 14, 2017; Accepted date: July 20, 2017; Published date: July 25, 2017

Copyright: (c) 2017 Guimaraes IS, et al. This is an open-access article distributed under the terms of the Creative Commons Attribution License, which permits unrestricted use, distribution, and reproduction in any medium, provided the original author and source are credited.

\begin{abstract}
Cancer is one of the leading causes of death worldwide. Every year 8.2 million people die from the disease. In this context, breast and ovarian cancer are the most incidental among women. Elucidation of cell growth pathways and the observation that these pathways are altered in human cancer have encouraged the search for specific inhibitors. The phosphatidylinositol-3cinase (PI3K)/Protein kinase b (AKT)/Mammalian Target of Rapamycin (mTOR) is an important pathway involved in cell growth, tumorigenesis, cell invasion, and resistance to therapies. This pathway is often activated in breast and ovarian cancers and the deregulation of its signaling can contribute to tumor growth, angiogenesis and metastasis. Metformin is one of the most commonly prescribed antidiabetic drugs in the world whose anticancer effects, mediated by reduced mTOR signaling, have become notable. Therefore, this review provides an overview of signaling pathway PI3K/AKT/mTOR in the ovarian and breast cancers as well as for target therapies of mTOR signaling, with an emphasis on its mechanisms, clinical applicability and future perspectives.
\end{abstract}

Keywords: Breast cancer; Ovarian cancer; mTOR pathway; mTOR inhibitors; Metformin

\section{Introduction}

The mTOR is a serine/threonine kinase ubiquitously expressed in mammalian cells being part of the PI3K/AKT pathway (Figure 1) [1,2]. In cells, mTOR is present in two distinct complexes, mTOR Complex 1 (mTORC1) and mTOR Complex 2 (mTORC2) that together regulate a variety of processes including proliferation, differentiation, metabolism, motility, survival, autophagy and angiogenesis [3-5]. Furthermore, the mTOR pathway is frequently hyperactivated in a number of human malignancies, including breast and ovarian cancer [6], therefore it is considered as a promising therapeutic target and a hotspot in cancer research.

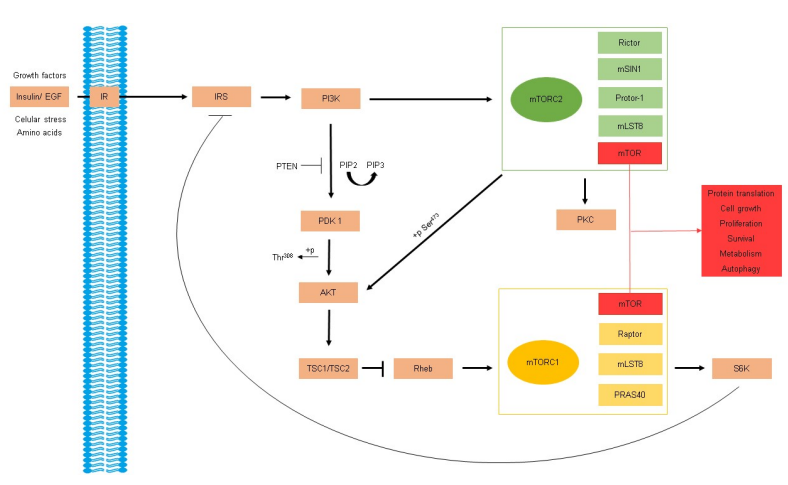

Figure 1: Overview of $\mathrm{Pl} 3 \mathrm{~K} / \mathrm{AKT} / \mathrm{mTOR}$ signaling pathway.
Preclinical studies have confirmed the anticancer effects of mTOR inhibitors in breast and ovarian cancer and further understanding of the molecular mechanism in PI3K/AKT/mTOR cascade is needed to develop optimized therapeutic regimens [6]. Combination therapies of mTOR inhibitor with agents such as cytotoxic chemotherapy, hormonal therapy, receptor tyrosine kinase inhibitors and vascular endothelial growth factor (VEGF) inhibitors are being intensively studied and appear to be promising.

Importantly, new players in mTOR signaling pathway have emerged with therapeutic potentials such as the antihyperglycemic drug metformin. Metformin, oral safe and well-tolerated drug, has been associated with reduced cancer risk in observational studies $[7,8]$. Beyond glucose lowering, metformin has shown in vitro promising results regarding reduction of cell proliferation and protein synthesis in breast and ovarian malignancies [9-11]. In this review, we provide a brief outline of our current understanding of the mTOR signaling pathway and discuss the clinical trial evidence available to date.

\section{The mTOR Pathway}

mTOR is a highly conserved intracellular serine/threonine kinase found practically in all mammalian cells. Under physiological conditions, mTOR modulates several processes, including protein translation, cell growth, proliferation, survival, metabolism, and autophagy [12-16]. mTOR is a component of two major intracellular signaling complexes, mTORC1 and mTORC2, which differ from each other in composition and functionality. mTORC1 consists of mTOR, raptor (regulatory associated protein of mTOR), PRAS40 (proline-rich AKT substrate $40 \mathrm{kDa}$ ), and mLST8 (mammalian lethal with sec-13); whereas mTORC2 is composed of mTOR, rictor (raptor independent companion of mTOR), mSIN1 (mammalian stress-activated protein 
kinase interacting protein 1), mLST8 and Protor-1 (protein observed with rictor-1) [14].

Diverse environmental signals, including growth factors (e.g. insulin, insulin-like growth factor 1 (IRS-1), epidermal growth factor (EGF), nutrients (e.g. amino acids) and cellular stress, regulate mTORC1 signaling [17-19]. After activation, mTORC1 phosphorylates a range of substrates, such as the $40 \mathrm{~S}$ ribosomal protein $\mathrm{S} 6$ kinase (p70S6K), 4E-binding protein 1 (4E-BP1) and UNC-51-like kinase 1 (ULK1) $[1,2]$. p70S6K and 4E-BP1 associate with mRNAs and regulate both mRNA translation initiation and progression, thus enhancing protein synthesis [20,21]. ULK1, in turn, modulates autophagy pathways $[2,22,23]$. On the other hand, and in contrast with the well described cellular roles of mTORC1, the function of mTORC2 is still not fully elucidated. However, it is known that mTORC2 promotes the activation of several kinases such as AKT and protein kinase C (PKC), and regulates the cytoskeleton organization [14,24-26].

It has been described that mTORC1 is activated by growth factors through the PI3K/AKT pathway. Most of the growth factors interact with receptor tyrosine kinases (RTK), upstream from the PI3K pathway, leading to the phosphorylation of phosphatidylinositol-4,5bisphosphate (PIP2) to generate phosphatidylinositol-3,4,5trisphosphate (PIP3). PIP3 serves as a docking site for 3'phosphoinositide-dependent kinase 1 (PDK1) and AKT, resulting in the phosphorylation at threonine 308 (Thr308) and activation of AKT by PDK1 $[27,28]$. In turn, AKT phosphorylates the tuberous sclerosis 2 (TSC2), thereby inhibiting the Ras homolog enriched in brain (Rheb) GTPase activity of the TSC1/TSC2 complex. Rheb, in its GTP-bound state, can activate mTOR $[29,30]$. Nonetheless, the upstream regulators of mTORC2 remain poorly characterized. Recently, in vitro kinase assays have shown that growth factors can activate mTORC2 [31]. The mTORC2 complex contributes to complete AKT activation by phosphorylating AKT at serine 473 (Ser473) [14,32].

Physiologically, some of the components of the PI3K/AKT/mTOR pathway are inhibited by proteins, such as the phosphatase and tensin homologue deleted on chromosome ten (PTEN) and the inositol polyphosphate 4-phosphatase type II (INPP4B), as well as by the TSC1/TSC2 complex [33-35]. PTEN acts on the D3 phosphorylated position of PIP3, promoting the formation of PIP2, thereby preventing the activation of AKT and PDK-1 [36,37]. Furthermore, INPP4B, a recently described lipid phosphatase, converts PIP2 to phosphatidylinositol monophosphate (PIP), thus regulating the PI3K activation $[38,39]$. Other negative regulators involved in this pathway are the PRAS40 and FK506-binding protein 8 (FKBP8), which prevent Rheb from activating mTORC1 $[40,41]$.

Importantly, mTORC1 negatively regulates growth factor signaling in two distinct manners. When activated by mTORC1, p70S6K directly phosphorylates the insulin receptor substrate-1 (IRS1), which promotes IRS1 degradation, and leads to decreased PI3K signaling and reduced AKT Thr308 phosphorylation [42-44]. In addition, mTORC1 directly interacts with IRS1 via Raptor, and phosphorylates IRS1 at Serine 636/639 (Ser636/639), hence, interfering with its association with PI3K [45].

\section{The Role of mTOR in Breast and Ovarian Cancer}

In the last few years, significant advances have been made in understanding the role of mTOR in cancer development and progression. Increased mTOR signaling in cancers has been implicated in tumorigenesis, promotion of cell survival, angiogenesis, invasion, tumor growth, patient prognosis and resistance to standard therapies [46].

mTOR activation involves loss of PTEN expression or function, mutation or amplification of the PI3K, amplification of AKT and inactivation or mutations of AKT-associated mTOR-regulatory proteins such as TSC1/TSC2 [47]. Additionally, aberrant activation of p70S6K and eIF4E has been reported in various human cancers, in which they correlate with tumor aggressiveness and poor disease prognosis [48-51]. The mTOR pathway can also be activated via exogenous oncogenes, including mutated or overexpressed RTKs, such as insulin-like growth factor 1 receptor (IGFR-1), platelet-derived growth factor receptor (PDGFR), and human epidermal growth factor receptors 1-4 (HER1-4) [52-55].

\section{Ovarian cancer}

Ovarian cancer is the most lethal gynecologic malignancy, and the fifth cause of cancer-related death among women [56,57]. According to the American Cancer Society (ACS), 22,440 new cases of ovarian cancer and 14,080 related deaths are estimated in the U.S.A. in 2017. When diagnosed at early and localized stages, the 5-year survival rate of ovarian cancer patients is approximately $94 \%$. Nevertheless, most of the cases are detected as advanced and metastatic disease, in which cases it relapses within two years, and the patients' survival rate decreases to $27 \%$ mainly due to chemoresistance to the platinumtaxane based chemotherapy in the adjuvant setting [57-60].

Ovarian cancer comprises a heterogeneous group of diseases classified based on morphologic and molecular-genetic features [61,62]. Type I tumors are composed of low-grade serous, low-grade endometrioid, clear cell, mucinous and transitional (Brenner) carcinomas. On the other hand, type II tumors, which are highly aggressive and almost always present in advanced stage, include highgrade serous carcinoma, undifferentiated carcinoma, and carcinosarcoma $[63,64]$. High grade serous ovarian cancer is the most prevalent ovarian cancer subtype, accounting for about $85 \%$ of all ovarian cancer-related deaths [65], followed by the clear cell and endometrioid subtypes that occur at similar rates, and mucinous carcinomas, the less common form of the disease [66]. Of note, genetic alterations, as somatic mutations, gene amplifications, and deletions in ovarian cancer seem to be subtype-specific, supporting the heterogeneity of the molecular, chemoresistance and clinical profiles of the multiple manifestations of the disease [67-69].

Despite the strong body of evidences pointing to specific genetic variations involved in the development and progression of ovarian cancer, there is still debate with regard to prevalent mutations and their prevalence in the disease. The analysis of 500 high grade serous ovarian tumors was conducted by the Cancer Genome Atlas (TCGA) project, revealing that $96 \%$ of all ovarian cancer subtypes present mutations in the TP53 gene [65,68]. In agreement, a systematic analysis of the TCGA Pan-Cancer cohort, which included 3,281 tumors from 12 cancer types, reported the prevalence of mutated TP53 gene in $95 \%$ of the 316 ovarian serous carcinomas included in the study [47]. Also, less frequent but yet recurrent mutations were reported in the $R B 1, N F 1$, FAT3, CSMD3, GABRA6 and CDK12 genes [47,65]. There is probable genetic specificity within ovarian cancer subtypes. In this context, whereas TP53 mutations are highly incident amongst type II tumors, they rarely occur in type I tumors $[63,64]$. The opposite seems to occur with respect to the rare but carcinogenic mutations in the $K R A S$, $B R A F$ and $E R B B 2$ genes that are prevalent in low-grade ovarian carcinomas in comparison to the high grade tumors $[65,68]$. Moreover, 
ovarian clear cell tumors present mutations in the PIK3CA, TP53, $K R A S, P T E N$ genes with a frequency of $33 \%, 15 \%, 7 \%$, and $5 \%$, respectively $[70,71]$, whereas endometrioid ovarian tumors frequently have mutated CTNNB1 (encoding $\beta$-catenin), ARID1A, member of the SWI/SNF family, and PIK3CA genes [64]. The mucinous ovarian tumors present prevalent $K R A S$ gene mutations $[63,64,72]$.

A key controversial aspect related to the genetic variations underlying ovarian cancer development and progression, including chemo-resistance, relies on the PI3K/AKT/mTOR pathway. Bellacosa et al. [73] have documented that amplification of the $A K T$ genes coding for all of the protein isoforms seems to occur in $15 \%$ to $20 \%$ of high grade serous ovarian carcinoma cases. Furthermore, mutations or gene amplification of the PIK3CA gene, which code for the p110a catalytic subunit of the PI3K protein, have been detected in $30.5 \%$ of all ovarian cancers [74]. Intriguingly, the recent TCGA Pan-Cancer study showed that the PIK3CA gene is the second most common mutated gene, behind the TP53 gene only, occurring frequently (>10\%) in most cancer types, except ovarian serous carcinoma, kidney clear cell carcinoma, lung adenocarcinoma, and acute myeloid leukemia. Likewise, none of the ovarian serous carcinoma studied presented mutations in the $A K T 1$ gene [47]. Notwithstanding the fact that the TCGA Pan-Cancer study has focused exclusively on gene mutations, but not on gene amplification, the data are still conflicting with previous publications [47]. Nonetheless, ongoing clinical trials support the benefit of ovarian cancer patients from the pharmacological inhibition of the PI3K/AKT/mTOR pathway, therefore reinforcing the fact that solving ovarian cancer molecular profiling by means of characterizing the heterogeneity of its subtypes and their mutational landscape likely represents an opportunity to fight the disease using target therapies effective against specific aberrations [75-77].

\section{Breast cancer}

Breast cancer $(\mathrm{BC})$ is the most frequent malignancy, and the second cause of cancer-related deaths among women in the United States, where 252, 710 new cases of the disease and 40,610 related deaths are expected in the year of 2017 [58]. Worldwide, the scenario is dramatic as well, with more than 1 million new cases of $\mathrm{BC}$ diagnosed yearly [65]. Breast cancer comprises multiple diseases harboring different genetic alterations, whose subtypes respond differently to treatment, and are associated to distinct clinical outcomes $[78,79]$.

In 2000, Perou and colleagues proposed a more reliable method to stratify breast cancer based on gene expression profiling, resulting in four major subtypes: luminal, human epidermal growth factor receptor 2 (HER2)-enriched, normal breast and basal-like (BL). The luminal and HER2-enriched group benefit from hormonotherapy and antiHER2 immunotherapy, respectively [80-82]. Basal-like breast cancers are often referred to as triple-negative breast cancers (TNBC) because most tumor cells lack the expression of estrogen receptor (ER), progesterone receptor (PR) and HER2. However, only 75\% of TNBC are of the basal-like subtype [83]. Although chemotherapy remains the mainstay strategy to combat basal-like breast cancer, target therapy and/or novel and efficacious molecules are still unavailable, leading to poor clinical outcome and patients' death following short disease progression-free interval [84].

Advances in understanding the etiology and biology of breast cancer have led to the identification of key targets among multiple signaling pathways involved in the development, malignant transformation, and survival of breast cancer cells. The PI3K/AKT/ mTOR pathway is commonly deregulated in breast cancer. Indeed, a systematic analysis of the TCGA Pan-Cancer cohort revealed that mutations in PIK3CA are frequent in breast cancer $(33.6 \%$ of the 763 primary breast cancers included in the study), being specifically enriched in luminal, ER+ subtype tumors. Moreover, PIK3CA mutations occur in breast cancer at a relatively high average variant allele fraction, thus enabling to infer early appearance of the genetic aberrations during tumorigenesis [47]. In addition to the putative involvement of PIK3CA mutations in breast cancer initiation, there is a strong body of evidences pointing to a critical role of the anomalous expression and activity of the $\mathrm{PI} 3 \mathrm{~K} / \mathrm{AKT} / \mathrm{mTOR}$ pathway in drug resistance [85]. Of clinical relevance, PI3K activation has been implicated in resistance to endocrine therapy in patients with ER+ breast cancer [86]. Therefore, means to identify which ER+breast cancer patients may require $\mathrm{PI} 3 \mathrm{~K} / \mathrm{mTOR}$ inhibition could facilitate a more accurate selection of patient populations for treatment, particularly in the adjuvant setting.

Interestingly the three main breast cancer subtypes display a remarkable difference within their mutational spectra. Mutations in the PIK3CA gene have been significantly associated with luminal breast tumors (45\%). In turn, the HER2-enriched subtype has been characterized by HER2 amplification (80\%), and high frequency of mutated PIK3CA (39\%) and TP53 (72\%) genes. In contrast, basal-like tumors have been associated to a frequency of $9 \%$ of mutations in the PIK3CA gene, and high frequency of TP53 mutated gene (80\%) [65]. Intriguingly, the PI3K pathway has been described as aberrantly activated at high frequency in basal-like breast cancer, thus enabling the postulation that alternative mechanisms are elicited by these tumor cells to warrant the phenomena. This might include loss of expression of the INPP4B and PTEN genes or amplification of the PIK3CA gene [87]. Basal-like tumors also exhibit frequent amplification of the KRAS (32\%), BRAF (30\%), and epidermal growth factor receptor (EGFR) (23\%) genes, contributing with constitutive activation of the $\mathrm{PI} 3 \mathrm{~K} / \mathrm{AKT} / \mathrm{mTOR}$ pathway [65].

Both breast basal-like and ovarian serous tumors are diseases related to patient's poor clinical outcome, and share common genetic features, such as the $R B 1$ gene loss, the $B R C A 1$ gene inactivation, the overexpression of the $A K T 3$ gene, the $M Y C$ gene amplification, and the high frequency of TP53 gene mutation [65].

\section{mTOR Inhibitors in Cancer Therapy}

\section{Rapamycin and its derivatives}

The mTOR serine/threonine kinase is a multiprotein complex and it is directly involved in many cell signaling pathways and many aberrations of the mTOR implicated in human cancer. mTOR inhibitors studied in clinical trials for cancer treatment showed that tumor cells with mutations in p53 or PTEN are susceptible to mTOR inhibitors [88].

mTOR inhibitors could be categorized in first and secondgeneration-presenting a wide variety of target and mechanism. The first-generation mTOR inhibitors include rapamycin and its analogues (sirolimus, temsirolimus, everolimus) that employ allosteric mechanism to block, whereas second generation mTOR inhibitors (AZD8055, Torin1, PP242, PP30) have as target ATP binding site to impede kinase activity of both mTORC1 and mTORC2 [89].

Rapamycin, a macrocyclic lactone isolated from the soil bacterium Streptomyces hygroscopicus, first discovered in 1975, has diverse clinical applications as an anti-fungal, immunosuppressant and anti- 
cancer drug [90,91]. Nevertheless, rapamycin has limited bioavailability due to its poor aqueous solubility. In an effort to improve its pharmacokinetics, several rapamycin analogues, named rapalogs, have been developed, such as the mTOR inhibitors temsirolimus (CCI-779), everolimus (RAD001) and ridaforolimus (MK-8669/AP23573) [4,92,93]. Rapamycin and its derivates exhibit a safe toxicity profile, being the side effects skin rashes and mucositis dose-dependent [94]. Other symptoms commonly described are fatigue, nausea, anaemia, hypertriglyceridemia, hypercholesterolemia and neutropenia [95]. Furthermore, temsirolimus and sirolimus are associated with significant rate of pulmonary toxicity [94,95]. Rare side effects of the aforesaid drugs included interstitial lung disease, risk of secondary lymphoma, and reactivation of latent infections [69].

The precise mechanisms of mTOR inhibition by rapalogs are not fully understood. However, evidences point to the allosteric inhibition of mTORC1. In mammalian cells, the rapalogs associate with the intracellular receptor FK506 binding protein 12 (FKBP12). Then, this complex interacts with the FKBP12-rapamycin binding (FRB) domain, inhibiting allosterically the mTOR kinase activity. It is widely believed that rapalogs would be therapeutically effective by blocking the mTORC1's phosphorylation activity of S6K and 4EBPs, which are key upstream regulators of protein synthesis, cell proliferation, cell-cycle progression and angiogenesis [96,97]. Three different mechanisms of action have been proposed for rapamycin. Firstly, the binding of the FKBP-12-rapamycin complex to mTOR that could lead to dephosphorylation of downstream effector molecules such as S6K1 and 4E-BP1 [98]. Secondly, the FKBP-12-rapamycin complex competes with phosphatidic acid to bind to the FRB domain of mTOR, blocking mTOR kinase function [99]. Thirdly, the FKBP-12rapamycin complex bound to mTOR destabilises the mTOR-raptor4E-BP1/S6K1 scaffold complex, leading to dephosphorylation of S6K1 and 4E-BP1 $[13,100]$. However, the effects of rapamycin are dependent on cell type. This inhibitor only causes cell cycle arrest in a limited number of cell types and has modest effects on protein synthesis [101,102]. Moreover, rapamycin is a relatively poor inducer of autophagy [103]. Therefore, the clinical effects are extended for few cancers, such as cell carcinoma renal and lymphoma [96]. It may be explained, at least partly, by the fact rapamycin could not block the function of mTORC1 completely and showed little effect on mTORC2 complex in the majority of cell types [5,104]. Furthermore, PI3K pathway could be active due to feedback loop when mTORC1 is inhibited [105].

Some studies have shown that these compounds are able to disrupt the mTORC2 complex in a dose-, time- and cell type-dependent manner $[14,106,107]$. A possible mechanism by which rapamycin and rapalogs could inhibit mTORC2 relies on the interaction of newly synthesized mTOR molecules and rapamycin/rapalogs-FKBP12 complexes. In turn, this interaction would prevent mTOR from the interaction with RICTOR, inhibiting, thus, mTORC2. Indeed, it has been shown that prolonged exposure of cancer cells to rapamycin can promote its binding to mTOR before the assembly of the mTORC2 complex, with subsequent inhibition of the AKT-mediated signaling [14].

Two mTOR inhibitors have been approved for clinical use in cancer. Everolimus (Afinitor ${ }^{\circledR}$ ), the first oral mTOR inhibitor to reach the oncology clinic, has been approved by the Food and Drug Administration (FDA) for the treatment of metastatic or unresectable pancreatic neuroendocrine tumors, advanced stage renal cell carcinoma, subependymal giant cell astrocytoma [108], progressive neuroendocrine tumors of the pancreatic origin [109], metastatic renal cell carcinoma and advanced ER+ [110], HER2 negative breast cancer [85]. Moreover, Tensirolimus (Torisel ${ }^{\circledR}$ ) was also approved by the FDA in 2007 for the management of advanced stage renal cell carcinoma (FDA). Both derivative of rapamycin form a complex with FKBP-12 and this complex then binds to the FRB domain and inhibits the mTOR function [111].

Several studies have been conducted to analyze the effectiveness of rapamycin and rapalogs alone and in combination with standard chemotherapy, hormonal therapy such as EGFR and anti-VEGF inhibitors in the treatment of several types of cancers such as breast, ovarian, cervical and endometrial [112]. Phase I-II trials are now ongoing with mTOR inhibitors in patients with breast and ovarian cancer.

For example, phase II studies are ongoing in order to test everolimus in combination with chemotherapy (cisplatin and gemcitabine) in patients with metastatic triple negative breast cancer (NCT01939418 and NCT01931163). Additionally, a recent study of breast cancer (BOLERO-3) demonstrated that the combination of everolimus with trastuzumab and vinorelbine significantly prolongs progression-free survival (PFS) in patients with trastuzumab-refractory and taxanepretreated, HER2+, advanced breast cancer [113]. Moreover, BOLERO-1 is an ongoing phase III, randomized, double-blind, placebo-controlled trial that will evaluate 717 patients with untreated metastatic HER2+ breast cancer randomly assigned to receive paclitaxel and trastuzumab with or without everolimus as first-line therapy [114]. A randomized placebo-controlled phase III trial (BOLERO-2) evaluated everolimus in combination with the aromatase inhibitor, exemestane, in postmenopausal women with HR+/HER2advanced breast cancer that progressed after previous letrozole or anastrozole therapy. This study showed a significant increase in PFS (10.6 versus 4.1 months) and led the approval of everolimus in combination with exemestane by FDA in 2012 [115].

Clinical studies have evaluated the aromatase inhibitor letrozole in combination with everolimus in patients with metastatic endometrial carcinoma (NCT01068249). Phase II study showed that patients with endometrioid histology and CTNNB1 mutations responded well for the treatment [116]. In another phase II study in patients with breast cancer (NCT00107016), everolimus significantly increased letrozole efficacy in neoadjuvant therapy with ER+ patients [117]. Studies have been conducted using aromatase inhibitor anastrozole with everolimus in patients with $\mathrm{ER}$ and/or $\mathrm{PR}+$ breast and gynecologic tumors as ovarian and endometrial cancer and the combination prolonged periods. Also, patients with multiple molecular alterations still benefited from therapy [118].

A phase II trial of ridaforolimus (AP2357) had been conducted in patients with advanced endometrial cancer and clinical benefit response was reported in 33\% of the patients [119]. Another phase II study using oral ridaforolimus in patients with advanced or recurrent endometrial cancer also showed partial response in $7.7 \%$ patients [120]. Also, temsirolimus is being evaluated with bevacizumab and in combination with chemotherapeutic agents in endometrial cancer cell lines, and results showed that it increases progesterone mRNA expression and inhibits ER mRNA expression [121]. Preliminary a phase II study conducted by Tinker and colleagues, 2013 using temsirolimus in patients with metastatic cervical cancer showed that $3.0 \%$ of patients had a partial response lasting 7.2 months, and $57.6 \%$ had stable disease with a median duration of 6.5 months [122]. 
Promising results also have been found in a study conducted by Campone et al. (2009) [123] to assess the safety and the pharmacokinetic interactions combining everolimus and paclitaxel in patients with breast cancer and ovarian carcinoma. Another phase II clinical study (GOG0268) that evaluates additional effects of the temsirolimus combined with paclitaxel/carboplatin therapy has been conducted in patients with stages III/IV clear cell adenocarcinoma $[112,124]$. However, some studies failed to show the efficiency of temsirolimus in patients with persistent/recurrent epithelial ovarian cancer/primary peritoneal cancer showing a modest activity of this mTOR inhibitor and the results were insufficient to justify further study in a phase III [125].

Although clinically promising, the efficacy of rapalogs is partially limited by the negative feedback loops in the MTOR pathway. With this regard, the exclusive inhibition of the mTORC1 complex by the rapalogs compromises the p70S6K-mediated feedback loop towards IRS-1, resulting in the activation of both the PI3K/AKT and MAPK/ERK pathways, hence promoting compensatory cell survival, and the acquisition of chemoresistant phenotype [5,44,93]. Efforts have been made to overcome the aforesaid clinical limitation by means of developing new generation mTOR inhibitors, which inhibit the catalytic activity of both mTORC1 and mTORC2 complexes.

\section{ATP-competitive inhibitors}

Although rapamycin is a potent allosteric mTORC1 inhibitor with clinical applications, a second generation ATP-competitive inhibitor has been developed, including Torin1, Torin2, PP242, PP30, KU0063794, WAY-600, WYE-687, WYE-354, XL-388, INK-128, AZD-2014, AZD8055 and OSI-027 [126-132]. The ATP-competitive inhibitors of mTOR directly inhibit the mTOR kinase activity, affecting both the mTORC1 and mTORC2 complexes. In comparison with rapamycin and rapalogs, ATP-competitive inhibitor is more potent and efficacious against cancer not only because of the complete inhibition of mTORC1 but also due to the additional inhibition of mTORC2, consequently preventing AKT phosphorylation at Ser473 $[104,130,133]$.

Studies which have been conducted with PP242 in colon cancer cells in vitro and in vivo showed decrease cell growth alone or in combination with MEK inhibitors [134]. Another ATP competitive inhibitor, Torin2, was developed to overcome the pharmacological limitations of Torin 1 and is also a potent inhibitor of ATR, ATM and DNA-PK $[135,136]$. Lung cancer cell treatment with Torin2 resulted in a prolonged block in negative feedback and consequent Thr308 phosphorylation on AKT. These effects were associated with strong growth inhibition in vitro [137].

At present, there are several clinical trials focused on the examination of new agents, such as AZD-8055, OSI-027, WYE125132 and INK128, in a variety of human hematological malignancies and solid tumors, including breast cancers [112]. Also some studies were conducted using GSK795 in patients with advanced platinum resistant ovarian and showed interesting results as tumor regressions and CA125 decreases [138]. Phase I study is ongoing in order to evaluate the safety and toxicity profile of AZD2014 in combination with paclitaxel in patients with ovarian cancer (NCT02193633).

In spite of the clinical improvements observed with the ATPcompetitive inhibitor when compared to the rapalogs, the literature still acknowledges significant limitations that outcome from compensatory cellular events. With this regard, it has been found that loss of the feedback on PI3K results in compensatory activation of the MAPK/ERK cascade by mTOR downstream effectors, such as 4E-BP1/ eIF4E, then, maintaining cell proliferation [139]. Furthermore, it has been shown that chronic inhibition of MTORC2 induces the activation of AKT by its phosphorylation on the residue Thr308 mediated by PDK-1, even in the absence of the priming Ser 473 phosphorylation. Altogether, the referred mechanisms ultimately drive the acquisition of the resistant phenotype by the cancer cells $[140,141]$.

\section{Dual mTOR/ PI3K inhibitors}

Scientists have explored to shed light on strategies to overcome the limitations by concomitantly targeting two molecules in the $\mathrm{PI} 3 \mathrm{~K} / \mathrm{AKT} / \mathrm{mTOR}$ pathway, PI3K and mTOR, whereas the resistance mTOR inhibitors cloud arise via feedback PI3K activation. This molecular knowledge has stimulated the development of news inhibitors termed dual PI3K-mTOR inhibitors that include NVPBEZ235, XL765, BGT226, PI-103, PF-04691502, PKI-587 and GDC-0980 [142-148]. Comparing with the other types of PI3K pathway inhibitors, dual PI3KmTOR inhibitors have the possible advantage of inhibiting all PI3K catalytic isoforms, mTORC1 and mTORC2 [6]. The catalytic sites of PI3K and mTOR share a high degree of sequence homology, thus enabling the abrogation of the catalytic activity of both PI3K and mTOR, consequently blocking downstream signaling related to cell proliferation, survival, and angiogenesis [142-145]. Therefore, these inhibitors may effectively turn off this pathway completely and display best efficacy in feedback inhibition normally observed with mTORC1 inhibitors [149]. However, it is not clear that dual PI3K-mTOR inhibitors will be tolerable at doses that effectively inhibit all p110 isoforms and mTOR [6].

The potential clinical value of the dual PI3K/mTOR inhibitors has been demonstrated by their significant inhibition of cell growth, and the induction of apoptosis and/or autophagy in a variety of tumor cancer cells [150-152], and these inhibitors have shown powerful effects in xenograft models of breast cancer [153], pancreatic cancer [154], melanoma [155], multiple myeloma [156], glioma [157], RCC [158], and acute myeloid leukemia (AML) [159].

In agreement, dual PI3K/mTOR inhibitors have entered clinical trials either as monotherapy as BEZ235/NVP-BEZ235, Novartis (NCT00620594) and BGT226, Novartis (NCT00600275 and NCT00742105) in advanced solid tumors and breast cancer, GDC-0980 (Genentech) (NCT00854126 and NCT00854152) in nonHodgkin lymphoma, PF-04691502, Pfizer (NCT00927823) and GSK2126458, GlaxoSmithKline (NCT00972686) in solid tumors or in combination with other therapeutic agents, for example XL765 (Exelixis) associated with erlotinib (NCT00777699), letrozole (NCT01082068) and temozolomide (NCT00704080) in non-small cell lung cancer, breast cancer and gliomas, respectively [112]. Both BEZ235 and XL765 have shown good tolerability, with adverse effects including diarrhea, anorexia and nausea [160]. Furthermore, the combined therapy using rapamycin and dual PI3K/mTOR kinase inhibitor (PI-103) has been shown to be efficacious against human ovarian cells in vivo [161].

\section{Metformin}

Metformin, a biguanide derivative, is a widely prescribed antihyperglycemic drug and is prescribed as the first-line therapy for type 2 diabetes mellitus (T2D), and insulin resistance syndromes [162]. 
It is a relatively safe drug, with known pharmacokinetics and a favorable safety profile. Importantly, metformin does not affect insulin secretion nor induces hypoglycemia in normal patients [163], aside from the fact that no teratogenic effects have been reported in the newborn of drug users. The main limited side effect of metformin is gastrointestinal discomfort, such as nausea and diarrhea, which are usually self-limited [164]. Rarely, the serious adverse effect of lactic acidosis is documented, which has been primarily restricted to patients with concomitant renal and hepatic disorders [165]. Metformin may also cause B12 deficiency in long-term therapy [166].

Several in vitro studies have shown that metformin treatment inhibits cell growth, induces apoptosis, and reduces invasion in a variety of human cancer cell lines, including breast and ovarian cancers [167-172]. These preclinical studies propose that metformin exerts its antineoplastic effects through multiple direct and indirect pathways; however the exact mechanism by which metformin acts remains poorly understood.

The indirect effects of metformin are related to the suppression of the transcription of key gluconeogenesis genes in the liver, and the increase of glucose uptake by skeletal muscle, thus leading to declines in circulating insulin and glucose levels [173]. Besides lowering insulin levels, metformin can indirectly increase insulin-like growth factorbinding protein 1 (IGFBP1) production, ultimately decreasing the bioavailability of IGF1 [174]. Insulin and IGFs are key regulators of metabolism and growth, promoting the development of cancer through the activation of the IRS/PI3K/AKT/mTOR and IRS/MAPK axis $[43,175]$.

In fact, the direct effects of metformin against cancer cells are mostly mediated by the activation of AMP-activated protein kinase (AMPK), and subsequent inhibition of mTOR, hence modulating cell metabolism and protein synthesis. Metformin must be actively transported into cells by the transmembrane protein organic cation transporter-1/2 (OCT1/OCT2) [176,177]. Once inside the cells, metformin inhibits the complex I of the mitochondrial respiratory chain, which leads to the disruption of the mitochondrial function, and to an increased ratio of adenosine monophosphate/adenosine triphosphate (AMP/ATP), mimicking cellular energy stress [178,179].

AMPK exists as heterotrimers composed of a catalytic subunit, and two regulatory subunits [180]. Each subunit is encoded by different genes, and has a unique role in the regulation and activation of AMPK. The subunit contains the activating phosphorylation site Threonine 172 (Thr172) [181], the subunit has the function of docking the protein to membranes [182], and the subunit binds to AMP or ATP [183]. AMPK can be allosterically activated by AMP, leading to the deposphorylation of the catalytic subunit by protein phosphatases. Moreover, AMPK activation requires the phosphorylation of the (Thr172) by upstream kinases [184-186]. The upstream master kinase that regulates AMPK activation is $L K B 1$, a tumor suppressor gene with relevance in many types of neoplasias, including breast cancer $[187,188]$. Once activated, AMPK regulates several effectors proteins, thus governing the activation of catabolic pathways (lipolysis and glycolysis), and the inhibition of anabolic pathways (gluconeogenesis, lipid and protein synthesis) [189-192].

As aforesaid, tumor cells often display alterations in PI3K/AKT/ mTOR pathway, which is a key signaling mechanism towards cellular growth and proliferation. Protein synthesis consumes a high proportion of ATP in the cell, thus mTOR is a major target of AMPK under conditions of metabolic stress. AMPK inhibits mTOR signaling through two distinct mechanisms: phosphorylation of TSC2, converting Rheb to its inactive GDP-bound form [193], and direct phosphorylation of Raptor, a subunit of the mTORC1 complex [194]. In addition, metformin inhibits the mTOR activity in the absence of TSC1/TSC2 and AMPK by suppressing RAG GTPases, which are involved in mTOR activation $[195,196]$.

The interest in metformin as anticancer drug emerged from numerous retrospective, population-based studies in diabetic patients. Studies have suggested that metformin reduces cancer incidence and/or mortality among T2D patients, compared to those taking other antidiabetic medications [7,8,197-202]. Prospective data concerning metformin use in non-diabetic cancer patients are beginning to emerge. Hadad et al. [203] performed a pilot study on a small cohort of patients with breast cancer revealing that the use of metformin (500-1000 $\mathrm{mg} /$ day) decreased tumor cell proliferation, estimated by Ki-67 staining and altered the expression of various genes including those involved in inflammation, metabolism and mTOR signaling. Similarly, metformin treatment has been associated with beneficial effects in non-diabetic breast cancer women, concerning Ki67 staining, and terminal deoxynucleotidyl transferase-mediated dUTP nick end labeling (TUNEL) scores [204]. However, Bonani et al. [205] have failed to demonstrate clinical benefit of metformin in breast cancer neoadjuvant setting through the evaluation of Ki67 expression. Nevertheless a different effect of metformin according to insulin resistance (homeostasis model assessment (HOMA) index) was noted, particularly in luminal $\mathrm{B}$ tumors, with a trend to a decreased proliferation in women with elevated HOMA index. Taken in conjunction, the state of the art knowledge about metformin and breast cancer has enabled authors to hypothesize that insulin resistance modulates both breast cancer biology and the antineoplasic actions of metformin [206,207].

There are more than 50 ongoing or upcoming clinical studies investigating metformin in cancer patients as monotherapy or in combined therapy with other antineoplasic agents [112]. For example, two clinical trials (NCT01529593/ NCT02145559) have been initiated aiming the evaluation of the treatment of advanced cancers, including breast cancer, with temsirolimus/sirolimus and metformin. In addition, an ongoing phase II study proposes to evaluate the combination of metformin, everolimus and letrozole in postmenopausal overweight or obese women with advanced receptor-positive breast cancer (NCT01627067).

\section{Conclusion}

Both highly lethal malignancies comprise deregulated and anomalously activated PI3K/AKT/mTOR pathways, hence emerging as eligible diseases to be fought with common targeted therapeutic strategies. In this context, early trials of mTOR inhibitors have shown some clinical benefit and, combinations of mTOR inhibitors with other treatment modalities have demonstrated clinical results without significant additional toxicity. Furthermore, the combination seems to be promising due to the fact that metformin inhibits mTOR, even in the absence of AMPK, through the decreased activation of IGFR-1/ MAPK, an important pathway related with resistance to mTOR inhibitors. Find below a summary of the main inhibitors mentioned in this paper. 


\section{References}

1. Hara K, Yonezawa K, Weng QP, Kozlowski MT, Belham C, et al. (1998) Amino acid sufficiency and mTOR regulate p70 S6 kinase and eIF-4E BP1 through a common effector mechanism. J Biol Chem 273: 14484-14494.

2. Jung CH, Jun CB, Ro SH, Kim YM, Otto NM, et al. (2009) ULK-Atg13 FIP200 complexes mediate mTOR signaling to the autophagy machinery. Mol Biol Cell 20: 1992-2003.

3. Laplante M, Sabatini DM (2012) mTOR signaling in growth control and disease. Cell 149: 274-293.

4. Liu Q, Thoreen C, Wang J, Sabatini D, Gray NS (2009) mTOR Mediated Anti-Cancer Drug Discovery. Drug Discov Today Ther Strateg 6: 47-55.

5. Guertin DA, Sabatini DM (2007) Defining the role of mTOR in cancer. Cancer Cell 12: 9-22.

6. Courtney KD, Corcoran RB, Engelman JA (2010) The PI3K pathway as drug target in human cancer. J Clin Oncol 28: 1075-1083.

7. Evans JM, Donnelly LA, Emslie-Smith AM, Alessi DR, Morris AD (2005) Metformin and reduced risk of cancer in diabetic patients. BMJ 330 1304-1305.

8. Bowker SL, Majumdar SR, Veugelers P, Johnson JA (2006) Increased cancer-related mortality for patients with type 2 diabetes who use sulfonylureas or insulin. Diabetes Care 8: 1990-1991.

9. Quinn BJ, Kitagawa H, Memmott RM, Gills JJ, Dennis PA (2013) Repositioning metformin for cancer prevention and treatment. Cell Metabolism 24: 469-480.

10. Pierotti MA, Berrino F, Gariboldi M, Melani C, Mogavero A, et al. (2013) Targeting metabolism for cancer treatment and prevention: metformin, an old drug with multi-faceted effects. Oncogene 32:1475-1487.

11. Lengyel E, Litchfield LM, Mitra AK, Nieman KM, Mukherjee A et al. (2015) Metformin inhibits ovarian cancer growth and increases sensitivity to paclitaxel in mouse models. Am J Obstet Gynecol 212: 479.

12. Kunz J, Henriquez R, Schneider U, Deuter-Reinhard M, Movva NR, et al. (1993) Target of rapamycin in yeast, TOR, is an essential phosphatidylinositol kinase homolog required for G1 progression. Cell 73: 585-596.

13. Kim DH, Sarbassov DD, Ali SM, King JE, Latek RR, et al. (2002) mTOR interacts with raptor to form a nutrient-sensitive complex that signals to the cell growth machinery. Cancer Cell 110: 163-175.

14. Sarbassov DD, Guertin DA, Ali SM, Sabatini DM (2005) Phosphorylation and regulation of Akt/PKB by the rictor-mTOR complex. Science 307: 1098-1101.

15. Wullschleger S, Loewith R, Hall MN (2006) TOR signaling in growth and metabolism. Cell 124: 471-484.

16. Duvel K, Yecies JL, Menon S, Raman P, Lipovsky AI, et al. (2010) Activation of a metabolic gene regulatory network downstream of mTOR complex 1. Mol Cell. 39: 171-183.

17. Sancak Y, Thoreen CC, Peterson TR, Lindquist RA, Kang SA, et al. (2007) PRAS40 is an insulin-regulated inhibitor of the mTORC1 protein kinase. Mol Cell 25: 903-915.

18. Sancak Y, Peterson TR, Shaul YD, Lindquist RA, Thoreen CC, et al. (2008) The Rag GTPases bind raptor and mediate amino acid signaling to mTORC1. Science 320: 1496-1501.

19. Liang Q, Zheng W, Lianyuan T, Yun W (2010) ER stress negatively regulates AKT/TSC/mTOR pathway to enhance autophagy. Autophagy 6: 239-247.

20. Jeno P, Ballou LM, Novak-Hofer I, Thomas G (1988) Identification and characterization $\mathrm{f}$ a mitogen-activated S6 kinase. Proc Natl Acad Sci 85: 406-410.

21. Hara K, Yonezawa K, Kozlowski MT, Sugimoto T, Andrabi K, et al. (1997) Regulation of eIF-4E BP1 phosphorylation by mTOR. J Biol Chem 272: 26457-26463.

22. Chan EY, Kir S, Tooze SA (2007) siRNA screening of the kinome identifies ULK1 as a multidomain modulator of autophagy. J Biol Chem 282: 25464-25474.
23. Hosokawa N, Hara T, Kaizuka T, Kishi C, Takamura A, et al. (2009) Nutrient-dependent mTORC1 association with the ULK1-Atg13-FIP200 complex required for autophagy. Mol Biol Cell 20: 1981-1991.

24. Jacinto E, Loewith R, Schmidt A, Lin S, Rüegg MA, et al. (2004) Mammalian TOR complex 2 controls the actin cytoskeleton and is rapamycin insensitive. Nat Cell Biol 6: 1122-1128.

25. Sarbassov DD, Ali SM, Kim DH, Guertin DA, Latek RR, et al. (2004) Rictor, a novel binding partner of mTOR, defines a rapamycin-insensitive and raptor-independent pathway that regulates the cytoskeleton. Curr Biol 14: 1296-1302.

26. Guertin DA, Stevens DM, Thoreen CC, Burds AA, Kalaany NY, et al (2006) Ablation in mice of the mTORC components raptor, rictor, or mLST8 reveals that mTORC2 is required for signaling to Akt-FOXO and PKCalpha, but not S6K1. Dev Cell 11: 859-871.

27. Alessi DR, James SR, Downes CP, Holmes AB, Gaffney PR, et al. (1997) Characterization of a 3-phosphoinositide-dependent protein kinase which phosphorylates and activates protein kinase B alpha. Curr Biol 7: 261-269.

28. Currie RA, Walker KS, Gray A, Deak M, Casamayor A, et al. (1999) Role of phosphatidylinositol 3,4,5-trisphosphate in regulating the activity and localization of 3-phosphoinositide-dependent protein kinase-1. Biochem J 337: 575-583.

29. Tee AR, Fingar DC, Manning BD, Kwiatkowski DJ, Cantley LC, et al. (2002) Tuberous sclerosis complex-1 and -2 gene products function together to inhibit mammalian target of rapamycin (mTOR)-mediated downstream signaling. Proc Natl Acad Sci 99: 13571-13576.

30. Potter CJ, Pedraza LG, Xu T (2002) Akt regulates growth by directly phosphorylating Tsc2. Nat Cell Biol 4: 658-665.

31. Yang Q, Inoki K, Ikenoue T, Guan KL (2006) Identification of Sin 1 as an essential TORC2 component required for complex formation and kinase activity. Genes Dev 20: 2820-2832.

32. Sarbassov DD, Ali SM, Sengupta S, Sheen JH, Hsu PP, et al. (2006) Prolonged rapamycin treatment inhibits mTORC2 assembly and Akt/ PKB. Mol Cell 22: 159-168.

33. Li J, Yen C, Liaw D, Podsypanina K, Bose S, et al. (1997) PTEN, a putative protein tyrosine phosphatase gene mutated in human brain, breast, and prostate cancer. Sci 275: 1943-1947.

34. Rodgers SJ, Ferguson DT, Mitchell CA, Ooms LM (2017) Regulation of PI3K effector signalling in cancer by the phosphoinositide phosphatases. Biosci Rep 37: 2 .

35. Eramo MJ, Mitchell CA2 (2016) Regulation of PtdIns(3,4,5)P3/Akt signalling by inositol polyphosphate 5-phosphatases. Biochem Soc Trans 44: 240-252.

36. Maehama T, Dixon JE (1998) The tumor suppressor, PTEN/MMAC, dephosphorylates the lipid second messenger, phosphatidylinositol 3,4,5trisphosphate. J Biol Chem 273: 13375-13378.

37. Cantley LC, Neel BG (1999) New insights into tumor suppression: PTEN suppresses tumor formation by restraining the phosphoinositide 3kinase/AKT pathway. Proc Natl Acad Sci 96: 4240-4245.

38. Ivetac I, Gurung R, Hakim S, Horan KA, Sheffield DA, et al. (2009) Regulation of $\mathrm{PI}(3) \mathrm{K} / \mathrm{Akt}$ signalling and cellular transformation by inositol polyphosphate 4-phosphatase-1. EMBO Rep 10: 487-493.

39. Fedele CG, Ooms LM, Ho M, Vieusseux J, O'Toole SA, et al. (2010) Inositol polyphosphate 4-phosphatase II regulates PI3K/Akt signaling and is lost in human basal-like breast cancers. Proc Natl Acad Sci U S A 107: 22231-22236.

40. Zhang Y, Gao X, Saucedo LJ, Ru B, Edgar BA, et al. (2003) Rheb is a direct target of the tuberous sclerosis tumour suppressor proteins. Nat Cell Biol 5: 578-581.

41. Saucedo LJ, Gao X, Chiarelli DA, Li L, Pan D, et al. (2003) Rheb promotes cell growth as a component of the insulin/TOR signalling network. Nat Cell Biol 5: 566-571.

42. Um SH, Frigerio F, Watanabe M, Picard F, Joaquin M, et al. (2004) Absence of S6K1 protects against age- and diet-induced obesity while enhancing insulin sensitivity. Nature 431: 200-205. 
Citation: Guimarães IS, Tessarollo NG, dos Santos DZ, de Souza MLM, Henriques TB, et al. (2017) Metformin and mTOR Inhibitors: Allies against Ovarian and Breast Cancers. J Carcinog Mutagen 8: 299. doi:10.4172/2157-2518.1000299

Page 8 of 11

43. Harrington LS, Findlay GM, Gray A, Tolkacheva T, Wigfield S, et al (2004) The TSC1-2 tumor suppressor controls insulin-PI3K signaling via regulation of IRS proteins. J Cell Biol 166: 213-223.

44. Carracedo A, Ma L, Teruya-Feldstein J, Rojo F, Salmena L, et al. (2008) Inhibition of mTORC1 leads to MAPK pathway activation through a PI3K-dependent feedback loop in human cancer. J Clin Invest 118: 3065-3074

45. Tzatsos A1 (2009) Raptor binds the SAIN (Shc and IRS-1 NPXY binding) domain of insulin receptor substrate-1 (IRS-1) and regulates the phosphorylation of IRS-1 at Ser-636/639 by mTOR. J Biol Chem 284 22525-22534.

46. Gomez-Pinillos A, Ferrari AC (2012) mTOR signaling pathway and mTOR inhibitors in cancer therapy. Hematol Oncol Clin North Am 26: 483-505.

47. Kandoth C, McLellan MD, Vandin F, Ye K (2013) Mutational landscape and significance across 12 major cancer types. Nature 502: 333-339.

48. Bärlund M, Forozan F, Kononen J, Bubendorf L, Chen Y, et al. (2000) Detecting activation of ribosomal protein $S 6$ kinase by complementary DNA and tissue microarray analysis. J Natl Cancer Inst 92: 1252-1259.

49. van der Hage JA, van den Broek LJ, Legrand C, Clahsen PC, Bosch CJ, et al. (2004) Overexpression of P70 S6 kinase protein is associated with increased risk of locoregional recurrence in node-negative premenopausal early breast cancer patients. Br J Cancer 90: 1543-1550.

50. Lin HJ, Hsieh FC, Song H, Lin J (2005) Elevated phosphorylation and activation of PDK-1/AKT pathway in human breast cancer. Br J Cancer 93: 1372-1381.

51. Ip CK, Wong AS (2012) Exploiting p70 S6 kinase as a target for ovarian cancer. Expert Opin Ther Targets 16: 619-630.

52. McGlade CJ, Ellis C, Reedijk M, Anderson D, Mbamalu G, et al. (1992) SH2 domains of the p85 alpha subunit of phosphatidylinositol 3-kinase regulate binding to growth factor receptors. Mol Cell Biol 12: 991-997.

53. Klippel A, Escobedo JA, Fantl WJ, Williams LT (1992) The C-terminal SH2 domain of $\mathrm{p} 85$ accounts for the high affinity and specificity of the binding of phosphatidylinositol 3-kinase to phosphorylated plateletderived growth factor beta receptor. Mol Cell Biol 12: 1451-1459.

54. Peles E, Lamprecht R, Ben-Levy R, Tzahar E, Yarden Y (1992) Regulated coupling of the Neu receptor to phosphatidylinositol 3'-kinase and its release by oncogenic activation. J Biol Chem 267: 12266-12274.

55. Soltoff SP, Carraway KL, Prigent SA, Gullick WG, Cantley LC (1994) ErbB3 is involved in activation of phosphatidylinositol 3-kinase by epidermal growth factor. Mol Cell Biol 14: 3550-3558.

56. Ko SY, Naora H (2014) Therapeutic strategies for targeting the ovarian tumor stroma. World J Clin Cases 16: 194-200.

57. Siegel R, Naishadham D, Jemal A (2013) Cancer statistics. CA: A Cancer Journal for Clinicians 63: 11-30.

58. American Cancer Society (ACS) (2017) Cancer Facts \& Statistics 2017.

59. Agarwal R, Kaye SB (2003) Ovarian cancer: strategies for overcoming resistance to chemotherapy. Nat Rev Cancer 3: 502-516.

60. Rangel LB, Sherman-Baust CA, Wernyj RP, Schwartz DR, Cho KR, et al. (2003) Characterization of novel human ovarian cancer-specific transcripts (HOSTs) identified by serial analysis of gene expression. Oncogene 22: 7225-7232.

61. Scully R, Sobin L (1999) Histological typing of ovarian tumours, volume 9: Springer Berlin, New York, USA.

62. Seidman JD, Russell P, Kurman RJ (2002) Surface epithelial tumors of the ovary. In: Kurman RJ, editor. Blaustein's Pathology of the Female Genital Tract (5th ed). Springer Verlag, New York, USA, pp. 791-904.

63. Shih IeM, Kurman RJ (2004) Ovarian tumorigenesis: a proposed model based on morphological and molecular genetic analysis. Am J Pathol 164: 1511-1518.

64. Kurman RJ, Shih IeM (2010) The origin and pathogenesis of epithelial ovarian cancer: a proposed unifying theory. Am J Surg Pathol 34: 433-443.

65. Cancer Genome Atlas Network (2012) Comprehensive molecular portraits of human breast tumours. Nature 490: 61-70.
66. Brown J, Frumovitz M (2014) Mucinous tumors of the ovary: current thoughts on diagnosis and management. Curr Oncol Rep 16: 389.

67. Bowtell DD1 (2010) The genesis and evolution of high-grade serous ovarian cancer. Nat Rev Cancer 10: 803-808.

68. Kurman RJ, Shih IeM (2010) The origin and pathogenesis of epithelial ovarian cancer: a proposed unifying theory. Am J Surg Pathol 34: 433-443.

69. Leary A, Auclin E, Pautier P, Lhommé C (2013) The PI3K/Akt/mTOR Pathway in Ovarian Cancer: Biological Rationale and Therapeutic Opportunities. Proc Natl 8: 12.

70. Senturk S, Yao Z, Camiolo M, Stiles B, Rathod T, et al. (2014) p53î" is a transcriptionally inactive p53 isoform able to reprogram cells toward a metastatic-like state. Proc Natl Acad Sci U S A 111: E3287-3296.

71. Kuo KT, Mao TL, Jones S, Veras E, Ayhan A, et al. (2009) Frequent activating mutations of PIK3CA in ovarian clear cell carcinoma. Am J Pathol 174: 1597-1601

72. Soslow RA1 (2008) Histologic subtypes of ovarian carcinoma: an overview. Int J Gynecol Pathol 27: 161-174.

73. Bellacosa A, de Feo D, Godwin AK, Bell DW, Cheng JQ, et al. (1995) Molecular alterations of the AKT2 oncogene in ovarian and breast carcinomas. Int J Cancer 64: 280-285.

74. Campbell IG, Russell SE, Choong DY, Montgomery KG, Ciavarella ML, et al. (2004) Mutation of the PIK3CA gene in ovarian and breast cancer. Cancer Res 64: 7678-7681.

75. Mazzoletti M, Broggini M (2010) PI3K/AKT/mTOR inhibitors in ovarian cancer. Curr Med Chem 17: 4433-4447.

76. Janku F, Hong DS, Fu S, Piha-Paul SA, Naing A, et al. (2014) Assessing PIK3CA and PTEN in early-phase trials with PI3K/AKT/mTOR inhibitors. Cell Rep 6: 377-387.

77. Leary A, Auclin E, Pautier P, Lhommé C (2013) The PI3K/Akt/mTOR Pathway in Ovarian Cancer: Biological Rationale and Therapeutic Opportunities. Cell 6: 52.

78. Perou CM, Sørlie T, Eisen MB, van de Rijn M, Jeffrey SS, et al. (2000) Molecular portraits of human breast tumours. Nature 406: 747-752.

79. Sørlie T, Perou CM, Tibshirani R, Aas T, Geisler S, et al. (2001) Gene expression patterns of breast carcinomas distinguish tumor subclasses with clinical implications. Proc Natl Acad Sci 98: 10869-10874.

80. Harvey JM, Clark GM, Osborne CK, Allred DC (1999) Estrogen receptor status by immunohistochemistry is superior to the ligand-binding assay for predicting response to adjuvant endocrine therapy in breast cancer. J Clin Oncol 17: 1474-1481.

81. Slamon D, Eiermann W, Robert N, Pienkowski T, Martin M, et al. (2011) Adjuvant trastuzumab in HER2-positive breast cancer. N Engl J Med 365: 1273-1283.

82. Cuzick J, Sestak I, Baum M, Buzdar A, Howell A, et al. (2010) Effect of anastrozole and tamoxifen as adjuvant treatment for early-stage breast cancer: 10-year analysis of the ATAC trial. Lancet Oncol 11: 1135-1141.

83. Perou CM (2011) Molecular stratification of triple-negative breast cancers. Oncologist 16: 61-70.

84. Liedtke C, Mazouni C, Hess KR, André F, Tordai A, et al. (2008) Response to neoadjuvant therapy and long-term survival in patients with triplenegative breast cancer. J Clin Oncol 26: 1275-1281.

85. Burris HA 3rdl (2013) Overcoming acquired resistance to anticancer therapy: focus on the PI3K/AKT/mTOR pathway. Cancer Chemother Pharmacol 71: 829-842.

86. Loi S, Michiels S, Baselga J, Bartlett JM, Singhal SK, et al. (2013) PIK3CA Genotype and a PIK3CA Mutation-Related Gene Signature and Response to Everolimus and Letrozole in Estrogen Receptor Positive Breast Cancer. PlosOne 8(1) e53292.

87. Stemke-Hale K, Gonzalez-Angulo AM, Lluch A, Neve RM, Kuo WL, et al. (2008) An integrative genomic and proteomic analysis of PIK3CA, PTEN, and AKT mutations in breast cancer. Cancer Res 68: 6084-6091.

88. Huang S, Houghton PJ (2002) Inhibitors of mammalian target of rapamycin as novel antitumor agents: from bench to clinic. Curr Opin Investig Drugs 3: 295-304. 
89. Guertin DA, Sabatini DM (2009) The pharmacology of mTOR inhibition. Sci Signal 2: pe24.

90. Vezina C, Kudelski A, Sehgal SN (1975) Rapamycin (AY-22,989), a new antifungal antibiotic. I. Taxonomy of the producing streptomycete and isolation of the active principle. J Antibiot 28: 721-726.

91. Singh K, Sun S, Vézina C (1979) Rapamycin (AY-22,989), a new antifungal antibiotic. IV. Mechanism of action. J Antibiot (Tokyo) 32: 630-645.

92. Alvarado Y, Mita MM, Vemulapalli S, Mahalingam D, Mita AC (2011) Clinical activity of mammalian target of rapamycin inhibitors in solid tumors. Target Oncol 6: 69-94.

93. Zaytseva YY, Valentino JD, Gulhati P, Evers BM (2012) mTOR inhibitors in cancer therapy. Cancer Lett 319: 1-7.

94. Vignot S, Faivre S, Aguirre D, Raymond E (2005) mTOR-targeted therapy of cancer with rapamycin derivatives. Ann Oncol 16: 525-537.

95. Duran I, Siu LL, Oza AM, Chung TB, Sturgeon J (2006) Characterisation of the lung toxicity of the cell cycle inhibitor temsirolimus. European J Cancer 42: 1875-1880.

96. Meric-Bernstam F, Gonzalez-Angulo AM (2009) Targeting the mTOR signaling network for cancer therapy. J Clin Oncol 27: 2278-87.

97. Efeyan A, Sabatini DM (2010) mTOR and cancer: many loops in one pathway. Curr Opin Cell Biol 22: 169-176.

98. Oldham S, Hafen E (2003) Insulin/IGF and target of rapamycin signaling: a TOR de force in growth control. Trends Cell Biol 13: 79-85.

99. Fang Y, Vilella-Bach M, Bachmann R, Flanigan A, Chen J (2001) Phosphatidic acid-mediated mitogenic activation of mTOR signaling. Science 294: 1942-1945.

100. Hara K, Maruki Y, Long X, Yoshino K, Oshiro N, et al. (2002) Raptor, a binding partner of target of rapamycin (TOR), mediates TOR action. Cell 110: $177-189$.

101. Pedersen S, Celis JE, Nielsen J, Christiansen J, Nielsen FC (1997) Distinct repression of translation by wortmannin and rapamycin. Eur J Biochem 247: 449-456.

102. Neshat MS, Mellinghoff IK, Tran C, Stiles B, Thomas G, et al. (2001) Enhanced sensitivity of PTEN-deficient tumors to inhibition of FRAP/ mTOR. Proc Natl Acad Sci USA 98: 10314-10319.

103. Takeuchi H, Kondo Y, Fujiwara K, Kanzawa T, Aoki H, et al. (2005) Synergistic augmentation of rapamycin-induced autophagy in malignant glioma cells by phosphatidylinositol 3-kinase/protein kinase B inhibitors. Cancer Res 65: 3336-3346

104. Thoreen CC, Kang SA, Chang JW, Liu Q, Zhang J, et al. (2009) An ATPcompetitive mammalian target of rapamycin inhibitor reveals rapamycinresistant functions of mTORC1. J Biol Chem 284: 8023-8032.

105. Wan X, Harkavy B, Shen N, Grohar P, Helman LJ (2007) Rapamycin induces feedback activation of Akt signaling through an IGF-1Rdependent mechanism. Oncogene 26: 1932-1940.

106. Brown EJ, Albers MW, Shin TB, Ichikawa K, Keith CT, et al. (1994) A mammalian protein targeted by G1-arresting rapamycin-receptor complex. Nature 369: 756-758.

107. Sabatini DM, Erdjument-Bromage H, Lui M, Tempst P, Snyder SH (1994) RAFT1: a mammalian protein that binds to FKBP12 in a rapamycindependent fashion and is homologous to yeast TORs. Cell 78: 35-43.

108. National Cancer Institute (2013) Available from: http://www.cancer.gov/ about-cancer/treatment/drugs/fda-everolimus

109. Motzer RJ, Escudier B, Oudard S, Hutson TE, Porta C, et al. (2008) Efficacy of everolimus in advanced renal cell carcinoma: a double-blind, randomised, placebo-controlled phase III trial. Lancet 372: 449-456.

110. Pavel ME, Hainsworth JD, Baudin E, Peeters M4, Hörsch D5, et al. (2011) Everolimus plus octreotide long-acting repeatable for the treatment of advanced neuroendocrine tumours associated with carcinoid syndrome (RADIANT-2): a randomised, placebo-controlled, phase 3 study. Lancet 378: 2005-2012.

111. Huang S, Houghton PJ (2003) Targeting mTOR signaling for cancer therapy. Curr Opin Pharmacol 3: 371-377.

112. Clinicaltrials.gov-rapamycin rapalogs hormonal therapy
113. André F, O'Regan R, Ozguroglu M, Toi M, Xu B, et al. (2014) Everolimus for women with trastuzumab-resistant, HER2-positive, advanced breast cancer (BOLERO-3): a randomised, double-blind, placebo-controlled phase 3 trial. Lancet Oncol 15: 580-591.

114. Hurvitz SA, Dalenc F, Campone M, O’Regan RM, Tjan-Heijnen VC, et al. (2013) A phase 2 study of everolimus combined with trastuzumab and paclitaxel in patients with HER2-overexpressing advanced breast cancer that progressed during prior trastuzumab and taxane therapy. Breast Cancer Res Treat 141: 437-446.

115. Gnant M, Greil R, Hubalek M, Steger G (2013) Everolimus in postmenopausal, hormone receptor-positive advanced breast cancer: summary and results of an austrian expert panel discussion. Breast Care 8: 293-299.

116. Slomovitz BM, Jiang Y, Yates MS, Soliman PT, Johnston T, et al. (2015) Phase II study of everolimus and letrozole in patients with recurrent endometrial carcinoma. J Clin Oncol 33: 930-936.

117. Baselga J, Semiglazov V, van Dam P, Manikhas A, Bellet M, et al. (2009) Phase II randomized study of neoadjuvant everolimus plus letrozole compared with placebo plus letrozole in patients with estrogen receptorpositive breast cancer. J Clin Oncol 27: 2630-2637.

118. Jennifer JW, Stacy LM, Aung N, Filip J, Sarina A, et al. (2014) Anastrozole and everolimus in advanced gynecologic and breast malignancies: activity and molecular alterations in the PI3K/AKT/mTOR pathway. Oncotarget 5: 3029-3038.

119. Colombo N, McMeekin S, Schwartz P, Kostka J, Sessa C, et al. (2007) A phase II trial of the mTOR inhibitor AP23573 as a single agent in advanced endometrial cancer. J Clin Oncol 25: 5516.

120. Mackay H, Welch S, Tsao MS, Biagi JJ, Elit L, et al. (2011) Phase II study of oral ridaforolimus in patients with metastatic and/or locally advanced endometrial cancer; NCIC CTG IND 192. J Clin Oncol 29: s5013.

121. Bae-Jump VL, Zhou C, Boggess JF, Gehrig PA (2009) Synergistic effect of rapamycin and cisplatin in endometrial cancer cells. Cancer 115: 3887-3896.

122. Temkin SM, Fleming G (2009) Current treatment of metastatic endometrial cancer. Cancer Control 16: 38-45.

123. Campone M, Levy V, Bourbouloux E, Berton Rigaud D, Bootle D, et al. (2009) Safety and pharmacokinetics of paclitaxel and the oral mTOR inhibitor everolimus in advanced solid tumours. Br J Cancer 100: 315-321.

124. Takatori E, Shoji T, Miura Y, Takada A, Takeuchi S, et al. (2014) Effective use of everolimus as salvage chemotherapy for ovarian clear cell carcinoma: a case report. Onco Targets Ther c7: 165-169.

125. Behbakht K, Sill MW, Darcy KM, Rubin SC, Mannel RS, et al. (2011) Phase II trial of the mTOR inhibitor, temsirolimus and evaluation of circulating tumor cells and tumor biomarkers in persistent and recurrent epithelial ovarian and primary peritoneal malignancies: a Gynecologic Oncology Group study. Gyn Onc 123: 19-26.

126. García-Martínez JM, Moran J, Clarke RG, Gray A, Cosulich SC, et al. (2009) $\mathrm{Ku}-0063794$ is a specific inhibitor of the mammalian target of rapamycin (mTOR). Biochem J 421: 29-42.

127. Feldman ME, Apsel B, Uotila A, Loewith R, Knight ZA, et al. (2009) Active-site inhibitors of mTOR target rapamycin-resistant outputs of mTORC1 and mTORC2. PLoS Biol 7: e38.

128. Yu K, Toral-Barza L, Shi C (2009) Biochemical, cellular, and in vivo activity of novel ATP-competitive and selective inhibitors of the mammalian target of rapamycin. Cancer Res 69: 6232-6240.

129. Liu Q, Chang JW, Wang J, Kang SA, Thoreen CC, et al. (2010) Discovery of 1-(4-(4-propionylpiperazin-1-yl)-3-(trifluoromethyl)phenyl)-9(quinolin-3-yl)benzo[h] $[1,6]$ naphthyridin-2 $(1 \mathrm{H})$-one as a highly potent, selective mammalian target of rapamycin (mTOR) inhibitor for the treatment of cancer. J Med Chem 53: 7146-7155.

130. Chresta CM, Davies BR, Hickson I (2010) AZD8055 is a potent, selective, and orally bioavailable ATP-competitive mammalian target of rapamycin kinase inhibitor with in vitro and in vivo antitumor activity. Cancer Res 70: $288-229$. 
131. Yu K, Shi C, Toral-Barza L (2010) Beyond rapalog therapy. Preclinical pharmacology and antitumor activity of WYE-1251, an ATP-competitive and -specific inhibitor of mTORC1 and mTORC2. Cancer Res 70: 621-631.

132. Bhagwat SV, Gokhale PC, Crew AP, Cooke A, Yao Y, et al. (2011) Preclinical characterization of OSI-027, a potent and selective inhibitor of mTORC1 and mTORC2: distinct from rapamycin. Mol Cancer Ther 10: 1394-1406.

133. Zhang H, Berel D, Wang Y, Li P, Bhowmick NA, et al. (2013) A comparison of Ku0063794, a dual mTORC1 and mTORC2 inhibitor, and temsirolimus in preclinical renal cell carcinoma models. PLoS One 8: e54918.

134. Blaser B, Waselle L, Dormond-Meuwly A, Dufour M, Roulin D, et al (2012) Antitumor activities of ATP-competitive inhibitors of mTOR in colon cancer cells. BMC Cancer 12: 86 .

135. Liu Q, Kang SA, Thoreen CC, Hur W, Wang J, et al. (2012) Development of ATP-competitive mTOR inhibitors. Methods Mol Biol 821: 447-460.

136. Patricelli MP, Nomanbhoy TK, Wu J, Brown H, Zhou D, et al. (2011) In situ kinase profiling reveals functionally relevant properties of native kinases. Chem Biol 18: 699-710.

137. Liu Q, Xu C, Kirubakaran S, Zhang X, Hur W, et al. (2013) Characterization of Torin, an ATP-competitive inhibitor of MTOR, ATM, and ATR. Cancer Res 73: 2574-2586.

138. Gungor H, Saleem A, Agarwal R, Blagden SP, Michael A, et al. (2011) Pharmacokinetic (PK)/pharmacodynamic (PD) analysis of escalating repeat doses of the AKT inhibitor GSK2141795 (GSK795) in patients (pts) with ovarian cancer. J Clin Oncol 29: 5064.

139. Cope CL, Gilley R, Balmanno K, Sale MJ, Howarth KD, et al. (2014) Adaptation to mTOR kinase inhibitors by amplification of eIF4E to maintain cap-dependent translation. J Cell Sci 127: 788-800.

140. Thoreen CC, Kang SA, Chang JW, Liu Q, Zhang J, et al. (2009) An ATPcompetitive Mammalian Target of Rapamycin Inhibitor Reveals Rapamycin resistant Functions of mTORC1. The J Biol Chem 284: 8023-8032.

141. Ducker GS, Atreya CE, Simko JP, Hom YK, Matli MR, et al. (2014) Incomplete Inhibition of phosphorylation of $4 \mathrm{E}-\mathrm{BP} 1$ as a mechanism of primary resistance to ATP-competitive mTOR inhibitors. Oncogene 33: 1590-1600.

142. Maira SM, Stauffer F, Brueggen J, Furet P, Schnell C, et al. (2008) Identification and characterization of NVP-BEZ235, a new orally available dual phosphatidylinositol 3-kinase/mammalian target of rapamycin inhibitor with potent in vivo antitumor activity. Molecul Cancer Ther 7: 1851-1863.

143. Park S, Chapuis N, Bardet V, Tamburini J, Gallay N, et al. (2008) PI-10, a dual inhibitor of Class IA phosphatidylinositide 3-kinase and mTOR, has antileukemic activity in AML. Leukemia 22: 1698-1706.

144. Mallon R, Feldberg LR, Lucas J, Chaudhary I, Dehnhardt C, et al. (2011) Antitumor efficacy of PKI-587, a highly potent dual PI3K/mTOR kinase inhibitor. Clin Cancer Res 17: 3193-3203.

145. Wallin JJ, Edgar KA, Guan J, Berry M, Prior WW, et al. (2011) GDC-0980 is a novel class I PI3K/mTOR kinase inhibitor with robust activity in cancer models driven by the PI3K pathway. Mol Cancer Ther 10 2426-2436.

146. Cheng H, Li C, Bailey S, Baxi SM, Goulet L, et al. (2012) Discovery of the Highly Potent PI3K/mTOR Dual Inhibitor PF-04979064 through Structure-Based Drug Design. ACS Med Chem Lett 4: 91-97.

147. Markman B, Tabernero J, Krop I, Shapiro GI, Siu L, et al. (2012) Phase safety, pharmacokinetic, and pharmacodynamic study of the oral phosphatidylinositol-3-kinase and mTOR inhibitor BGT226 in patients with advanced solid tumors. Ann Oncol 23: 2399-2408.

148. Papadopoulos KP, Tabernero J, Markman B, Patnaik A, Tolcher AW, et al. (2014) Phase I safety, pharmacokinetic, and pharmacodynamic study of SAR245409 (XL765), a novel, orally administered PI3K/mTOR inhibitor in patients with advanced solid tumors. Clin Cancer Res 20: 2445-2456.
149. O’Reilly KE, Rojo F, She QB, Solit D, Mills GB, et al. (2006) mTOR inhibition induces upstream receptor tyrosine kinase signaling and activates Akt. Cancer Res 66: 1500-1508.

150. Santiskulvong C, Konecny GE, Fekete M, Chen KY, Karam A, et al. (2011) Dual targeting of phosphoinositide 3-kinase and mammalian target of rapamycin using NVP-BEZ235 as a novel therapeutic approach in human ovarian carcinoma. Clin Cancer Res 17: 2373-2384.

151. Sanchez CG, Ma CX, Crowder RJ, Guintoli T, Phommaly C, et al. (2011) Preclinical modeling of combined phosphatidylinositol-3-kinase inhibition with endocrine therapy for estrogen receptor-positive breast cancer. Breast Cancer Res 13: 1-17.

152. O'Brien NA, McDonald K, Tong L, von Euw E, Kalous O, et al. (2014) Targeting PI3K/mTOR overcomes resistance to HER2-targeted therapy independent of feedback activation of AKT. Clin Cancer Res 20: 3507-3520.

153. Schnell CR, Stauffer F, Allegrini PR, O'Reilly T, McSheehy PM, et al. (2008) Effects of the dual phosphatidylinositol 3-kinase/mammalian target of rapamycin inhibitor NVP-BEZ235 on the tumor vasculature: implications for clinical imaging. Cancer Res 68: 6598-6607.

154. Cao P, Maira SM, Garcia-Echeverria C, Hedley DW (2009) Activity of a novel, dual PI3 kinase/mTor inhibitor NVP-BEZ235 against primary human pancreatic cancers grown as orthotopic xenografts. Br J Cancer 100: $1267-1276$.

155. Marone R, Erhart D, Mertz AC, Bohnacker T, Schnell C, et al. (2009) Targeting melanoma with dual phosphoinositide 3-kinase/mammalian target of rapamycin inhibitors. Molecul Cancer Res 7: 601-613.

156. McMillin DW, Ooi M, Delmore J, Negri J, Hayden P, et al. (2009) Antimyeloma activity of the orally bioavailable dual phosphatidylinositol 3- kinase/mammalian target of rapamycin inhibitor NVP-BEZ235. Cancer Res 69: 5835-5842.

157. Mallon R, Hollander I, Feldberg L, Lucas J, Soloveva V, et al. (2010) Antitumor efficacy profile of PKI-40, a dual phosphatidylinositol 3kinase/mammalian target of rapamycin inhibitor. Molecul Cancer Therap 9: 976-984.

158. Cho DC, Cohen MB, Panka DJ, Collins M, Ghebremichael M, et al. (2010) The efficacy of the novel dual PI3-kinase/mTOR inhibitor NVPBEZ235 compared with rapamycin in renal cell carcinoma. Clin Cancer Res 16: 3628-3638.

159. Park S, Chapuis N, Bardet V, Tamburini J, Gallay N, et al. (2008) PI-10, a dual inhibitor of Class IA phosphatidylinositide 3-kinase and mTOR, has antileukemic activity in AML. Leukemia 22: 1698-1706.

160. Wander SA, Hennessy BT, Slingerland JM (2011) Next-generation mTOR inhibitors in clinical oncology: how pathway complexity informs therapeutic strategy. J Clin Inves 121: 4.

161. Leary A, Auclin E, Pautier P, Lhommé C (2013) The PI3K/Akt/mTOR Pathway in Ovarian Cancer: Biological Rationale and Therapeutic Opportunities. Ovarian Cancer-A Clinical and Translational Update p. 275-302.

162. van Staa TP, Patel D, Gallagher AM, de Bruin ML (2012) Glucoselowering agents and the patterns of risk for cancer: a study with the general practice research database and secondary care data. Diabetologia 55: 654-665.

163. Barnett AH (2010) Avoiding hypoglycaemia while achieving good glycaemic control in type 2 diabetes through optimal use of oral agent therapy. Curr Med Res Opin 26: 1333-1342.

164. DeFronzo RA, Goodman AM (1995) Efficacy of metformin in patients with non-insulin-dependent diabetes mellitus. The Multicenter Metformin Study Group. N Engl J Med 333: 541-549.

165. Bodmer M, Meier C, Krahenbuhl S, Jick SS, Meier CR (2008) Metformin, sulfonylureas, or other antidiabetes drugs and the risk of lactic acidosis or hypoglycemia: a nested case-control analysis. Diabetes Care 31: 2086-2091.

166. de Jager J, Kooy A, Lehert P, Wulffelé MG, van der Kolk J, et al. (2010) Long term treatment with metformin in patients with type 2 diabetes and risk of vitamin B-12 deficiency: randomised placebo controlled trial. BMJ 340: c2181. 
167. Zakikhani M, Dowling R, Fantus IG, Sonenberg N, Pollak M (2006) Metformin is an AMP kinase-dependent growth inhibitor for breast cancer cells. Cancer Res 66: 10269-10273.

168. Ben IS, Laurent K, Loubat A, Giorgetti-Peraldi S, Colosetti P, et al. (2008) The antidiabetic drug metformin exerts an antitumoral effect in vitro and in vivo through a decrease of cyclin D1 level. Oncog 27: 3576-3586.

169. Liu B, Fan Z, Edgerton SM, Deng XS, Alimova IN, et al. (2009) Metformin induces unique biological and molecular responses in triple negative breast cancer cells. Cell Cycle 8: 2031-2040.

170. Alimova IN, Liu B, Fan Z, Edgerton SM, Dillon T, et al. (2009) Metformin inhibits breast cancer cell growth, colony formation and induces cell cycle arrest in vitro. Cell Cycle 8: 909-915.

171. Gotlieb WH, Saumet J, Beauchamp MC, Gu J, Lau S, et al. (2008) In vitro metformin anti-neoplastic activity in epithelial ovarian cancer. Gynecol Oncol 110: 246-250.

172. Rattan R, Graham RP, Maguire JL, Giri S, Shridhar V (2011) Metformin suppresses ovarian cancer growth and metastasis with enhancement of cisplatin cytotoxicity in vivo. Neoplasia 13: 483-491.

173. Leone A, Di Gennaro E, Bruzzese F, Avallone A, Budillon A (2014) New perspective for an old antidiabetic drug: metformin as anticancer agent. Cancer Treat Res 159: 355-376.

174. Firth SM, Baxter RC (2002) Cellular actions of the insulin-like growth factor binding proteins. Endocr Rev 23: 824-854.

175. Frasca F, Pandini G, Sciacca L, Pezzino V, Squatrito S, et al. (2008) The role of insulin receptors and IGF-I receptors in cancer and other diseases. Arch Physiol Biochem 114: 23-37.

176. Zhang L, Dresser MJ, Gray AT, Yost SC, Terashita S, et al. (1997) Cloning and functional expression of a human liver organic cation transporte. Mol Pharmacol 51: 913-921.

177. Graham GG, Punt J, Arora M, Day RO, Doogue MP, et al. (2011) Clinical pharmacokinetics of metformin. Clin Pharmacokinet 50: 81-98.

178. El-Mir MY, Nogueira V, Fontaine E, Avéret N, Rigoulet M, et al. (2000) Dimethylbiguanide inhibits cell respiration via an indirect effect targeted on the respiratory chain complex I. J Biol Chem 275: 223-228.

179. Owen MR, Doran E, Halestrap AP (2000) Evidence that metformin exerts its anti-diabetic effects through inhibition of complex 1 of the mitochondrial respiratory chain. Biochem J 348: 607-614.

180. Hardie DG, Carling D (1997) The AMP-activated protein kinase--fuel gauge of the mammalian cell? Eur J Biochem 246: 259-273.

181. Mitchelhill KI, Michell BJ, House CM, Stapleton D, Dyck J, et al. (1997) Posttranslational modifications of the 5'-AMP-activated protein kinase beta1 subunit. J Biol Chem 272: 24475-24479.

182. Warden SM, Richardson C, O'Donnell J Jr, Stapleton D, Kemp BE, et al. (2001) Post-translational modifications of the beta-1 subunit of AMP activated protein kinase affect enzyme activity and cellular localization. Biochem J 354: 275-283.

183. Hawley SA, Ross FA, Chevtzoff C, Green KA, Evans A, et al. (2010) Use of cells expressing gamma subunit variants to identify diverse mechanisms of AMPK activation. Cell Metab 11: 554-565.

184. Cheung PC, Salt IP, Davies SP, Hardie DG, Carling D (2000) Characterization of AMP-activated protein kinase gamma-subunit isoforms and their role in AMP binding. Biochem J $346 \mathrm{Pt}$ 3: 659-669.

185. Hawley SA, Boudeau J, Reid JL, Mustard KJ, Udd L, et al. (2003) Complexes between the LKB1 tumor suppressor, STRAD a/ß and MO25 $\mathrm{a} / \mathrm{B}$ are upstream kinases in the AMP-activated protein kinase cascade. J Biol 2: 28.

186. Shaw RJ, Kosmatka M, Bardeesy N, Hurley RL, Witters LA, et al. (2004) The tumor suppressor LKB1 kinase directly activates AMP-activated kinase and regulates apoptosis in response to energy stress. Proc Natl Acad Sci 101: 3329-3335.

187. Fenton H, Carlile B, Montgomery EA, Carraway H, Herman J, et al. (2006) LKB1 protein expression in human breast cancer. Appl Immunohistochem Mol Morphol 14: 146-153.
188. Dowling RJ, Zakikhani M, Fantus IG, Pollak M, Sonenberg N (2007) Metformin inhibits mammalian target of rapamycin-dependent translation initiation in breast cancer cells. Cancer Res 67: 10804-10812.

189. Foretz M, Carling D, Guichard C, Ferré P, Foufelle F (1998) AMPactivated protein kinase inhibits the glucose-activated expression of fatty acid synthase gene in rat hepatocytes. J Biol Chem 273: 14767-14771.

190. Hong YH, Varanasi US, Yang W, Leff T (2003) AMP-activated protein kinase regulates HNF4a transcriptional activity by inhibiting dimer formation and decreasing protein stability. J Biol Chem 278: 27495-27501.

191. Hardie DG1 (2004) The AMP-activated protein kinase pathway--new players upstream and downstream. J Cell Sci 117: 5479-5487.

192. Carling D1 (2004) AMPK. Curr Biol 14: R220.

193. Inoki $\mathrm{K}, \mathrm{Li} \mathrm{Y}, \mathrm{Xu} \mathrm{T}$, Guan KL (2003) Rheb GTPase is a direct target of TSC2 GAP activity and regulates mTOR signaling. Genes Dev 17: 1829-1834.

194. Gwinn DM, Shackelford DB, Egan DF, Mihaylova MM, Mery A, et al. (2008) AMPK phosphorylation of raptor mediates a metabolic checkpoint. Mol Cell 30: 214-226.

195. Kalender A, Selvaraj A, Kim SY, Gulati P, Brûlé S, et al. (2010) Metformin, independent of AMPK, inhibits mTORC1 in a rag GTPase-dependent manner. Cell Metab 11: 390-401.

196. Jiralerspong S, Palla SL, Giordano SH, Meric-Bernstam F, Liedtke C, et al. (2009) Metformin and pathologic complete responses to neoadjuvant chemotherapy in diabetic patients with breast cancer. J Clin Oncol 27: 3297-3302.

197. Currie CJ, Poole CD, Gale EA (2009) The influence of glucose-lowering therapies on cancer risk in type 2 diabetes. Diabetologia 52: 1766-1777.

198. Oppong BA, Pharmer LA, Oskar S, Eaton A, Stempel M, et al. (2014) The effect of metformin on breast cancer outcomes in patients with type 2 diabetes. Cancer Med 3: 1025-1034.

199. Libby G, Donnelly LA, Donnan PT, Alessi DR, Morris AD, et al. (2009) New users of metformin are at low risk of incident cancer: a cohort study among people with type 2 diabetes. Diabetes Care 32: 1620-1625.

200. Hernández-Díaz S, Adami HO (2010) Diabetes therapy and cancer risk: causal effects and other plausible explanations. Diabetologia 53: 802-808.

201. Landman GW, Kleefstra N, van Hateren KJ, Groenier KH, Gans RO, et al. (2010) Metformin associated with lower cancer mortality in type 2 diabetes: ZODIAC-16. Diabetes Care 33: 322-326.

202. Bodmer M, Meier C, Krähenbühl S, Jick SS, Meier CR (2010) Long-term metformin use is associated with decreased risk of breast cancer. Diabetes Care 33: 1304-1308.

203. Hadad S, Iwamoto T, Jordan L, Purdie C, Bray S, et al. (2011) Evidence for biological effects of metformin in operable breast cancer: a pre-operative, window-of-opportunity, randomized trial. Breast Cancer Res Treat 128: 783-794.

204. Niraula S, Dowling RJ, Ennis M, Chang MC, Done SJ, et al. (2012) Metformin in early breast cancer: a prospective window of opportunity neoadjuvant study. Breast Cancer Res Treat 135: 821-830.

205. Bonanni B, Puntoni M, Cazzaniga M, Pruneri G, Serrano D, et al. (2012) Dual effect of metformin on breast cancer proliferation in a randomized presurgical trial. J Clin Oncol 30: 2593-2600.

206. Johansson HA, Decensi A, Puntoni M, Cazzaniga M, Pruneri G, et al. (2012) Effects of metformin on markers of insulin resistance and on breast cancer proliferation: the putative role of IGFBP-1 as a predictive biomarker [abstract]. In: Proc 103rd Annu Meet Am Assoc Cancer Res. Chicago, IL. Philadelphia (PA).

207. Kasznicki J, Sliwinska A, Drzewoski J (2014) Metformin in cancer prevention and therapy. Ann Transl Med 2: 57. 